\title{
Impaired immune cell cytotoxicity in severe COVID-19 is IL-6 dependent
}

\author{
Alessio Mazzoni, ${ }^{1}$ Lorenzo Salvati, ${ }^{1}$ Laura Maggi, ${ }^{1}$ Manuela Capone, ${ }^{1}$ Anna Vanni, ${ }^{1}$ Michele Spinicci, ${ }^{1,2}$ Jessica Mencarini, ${ }^{1,2}$ \\ Roberto Caporale, ${ }^{3}$ Benedetta Peruzzi, ${ }^{3}$ Alberto Antonelli, ${ }^{1}$ Michele Trotta, ${ }^{2}$ Lorenzo Zammarchi, ${ }^{1,2}$ Luca Ciani, ${ }^{1}$ Leonardo Gori, ${ }^{1}$ \\ Chiara Lazzeri, ${ }^{4}$ Andrea Matucci, ${ }^{5}$ Alessandra Vultaggio, ${ }^{5}$ Oliviero Rossi, ${ }^{5}$ Fabio Almerigogna, ${ }^{1,5}$ Paola Parronchi,, \\ Paolo Fontanari, ${ }^{7}$ Federico Lavorini, ${ }^{1,8}$ Adriano Peris, ${ }^{4}$ Gian Maria Rossolini, ${ }^{1,9}$ Alessandro Bartoloni,, ${ }^{1,2}$ Sergio Romagnani, ${ }^{1}$ \\ Francesco Liotta, ${ }^{1,6}$ Francesco Annunziato, ${ }^{1,3}$ and Lorenzo Cosmi ${ }^{1,6}$ \\ 1Department of Experimental and Clinical Medicine, University of Florence, Florence, Italy. ${ }^{2}$ Infectious and Tropical Diseases Unit, ${ }^{3}$ Flow Cytometry Diagnostic Center and Immunotherapy (CDCI), ${ }^{4}$ Intensive \\ Care Unit and Regional Extracorporeal Membrane Oxygenation (ECMO) Referral Centre, ${ }^{5}$ Immunoallergology Unit, ${ }^{6}$ Immunology and Cell Therapy Unit, ${ }^{7}$ Cardiac Anesthesia and Intensive Care Unit, \\ ${ }^{8}$ Pneumology and Intensive Care Unit, and ${ }^{9}$ Clinical Microbiology and Virology Unit, Careggi University Hospital, Florence, Italy.
}

\begin{abstract}
BACKGROUND. Coronavirus disease 19 (COVID-19) is an emerging infectious disease caused by SARS-CoV-2. Antiviral immune response is crucial to achieve pathogen clearance; however, in some patients an excessive and aberrant host immune response can lead to an acute respiratory distress syndrome. The comprehension of the mechanisms that regulate pathogen elimination, immunity, and pathology is essential to better characterize disease progression and widen the spectrum of therapeutic options.
\end{abstract}

METHODS. We performed a flow cytometric characterization of immune cell subsets from 30 patients with COVID-19 and correlated these data with clinical outcomes.

RESULTS. Patients with COVID-19 showed decreased numbers of circulating T, B, and NK cells and exhibited a skewing of $\mathrm{CD8}^{+} \mathrm{T}$ cells toward a terminally differentiated/senescent phenotype. In agreement, CD4+ $\mathrm{T}$ and CD8+ $\mathrm{T}$, but also NK cells, displayed reduced antiviral cytokine production capability. Moreover, a reduced cytotoxic potential was identified in patients with COVID-19, particularly in those who required intensive care. The latter group of patients also showed increased serum IL-6 levels that inversely correlated to the frequency of granzyme A-expressing NK cells. Off-label treatment with tocilizumab restored the cytotoxic potential of NK cells.

CONCLUSION. The association between IL-6 serum levels and the impairment of cytotoxic activity suggests the possibility that targeting this cytokine may restore antiviral mechanisms.

FUNDING. This study was supported by funds from the Department of Experimental and Clinical Medicine of University of Florence (the ex-60\% fund and the "Excellence Departments 2018-2022 Project") derived from Ministero dell'Istruzione, dell'Università e della Ricerca (Italy).

\section{Introduction}

SARS-CoV-2 is the etiological agent of coronavirus disease 19 (COVID-19) and belongs to the same group of RNA viruses that caused SARS and Middle East respiratory syndrome (MERS) in the past (1-3). At the time of this publication, the WHO considered COVID-19 to be a new pandemic disease (4). As of June 30, 2020, there have been 10,185,374 confirmed COVID-19 cases globally; in Italy, 240,436 confirmed cases have been reported, with a total

Authorship note: A. Mazzoni and LS contributed equally to this work. F. Annunziato and $\mathrm{L}$. Cosmi contributed equally to this work.

Conflict of interest: The authors have declared that no conflict of interest exists. Copyright: () 2020, American Society for Clinical Investigation.

Submitted: March 27, 2020; Accepted: May 20, 2020; Published: August 4, 2020.

Reference information: J Clin Invest. 2020;130(9):4694-4703.

https://doi.org/10.1172/JCl138554. of 34,744 deaths (5). Coronaviruses are enveloped, nonsegmented, single-stranded, positive-sense RNA viruses named after the observation on electron microscopy of their corona- or crown-like surface projections that correspond to large surface spike proteins. Coronaviruses are classified in the Nidovirales order (6). These viruses are host specific and can infect humans and a variety of animals as well. The previously unknown coronavirus, named SARSCoV-2, was discovered in December 2019 in Wuhan, in the province of Hubei, China, and was sequenced and isolated by January 2020 (7-9). SARS-CoV, MERS-CoV, and SARS-CoV-2 are all in the genus Betacoronavirus (6). SARS-CoV-2 infection clinically presents with fever, nonproductive cough, and respiratory distress that tends to be more common in adults than in children (10). Coronavirus entry into host cells is mediated by the transmembrane spike (S) glycoprotein that forms homotrimers protruding from the viral surface (11). SARS-CoV and several SARS-related coronaviruses 

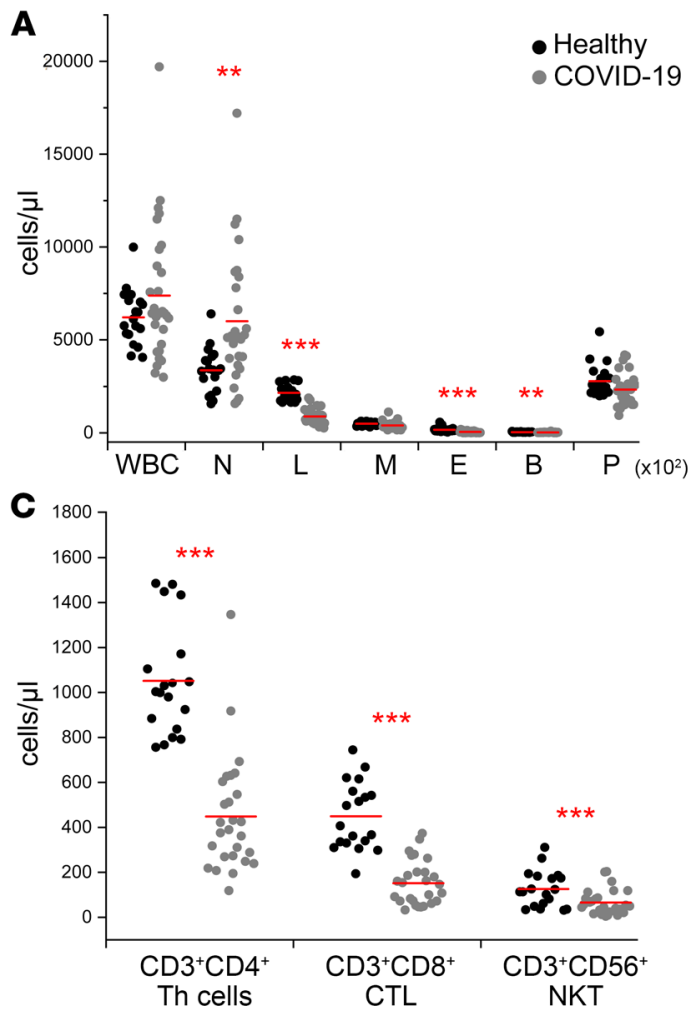

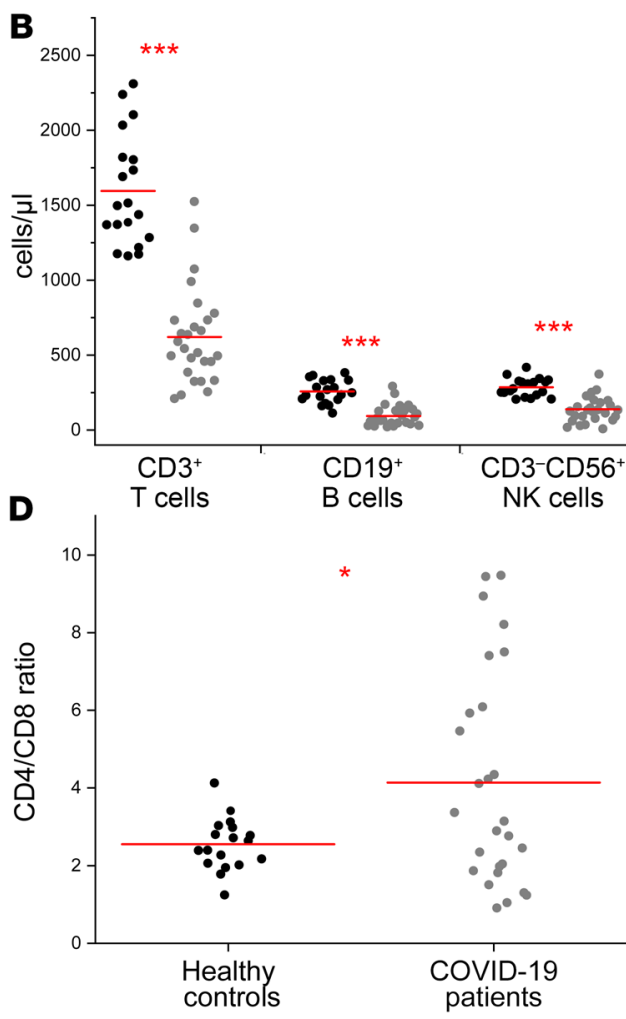

Figure 1. Absolute numbers of circulating WBCs in patients with COVID-19. (A) Absolute numbers of total WBCs, neutrophils (N), lymphocytes (L), monocytes $(M)$, eosinophils (E), basophils $(B)$, and platelets $(P)$ in healthy controls (black dots) and COVID-19 patients (gray dots). (B) Absolute numbers of $\mathrm{CD}^{+} \mathrm{T}$ cells, $\mathrm{CD} 19^{+}$ $B$ cells, and CD56 ${ }^{+}$NK cells in healthy controls (black dots) and COVID-19 patients (gray dots). (C) Absolute numbers of $\mathrm{CD}^{+} \mathrm{CD} 4^{+}$ Th cells, $\mathrm{CD3}^{+} \mathrm{CD}^{+}$cytotoxic $\mathrm{T}$ cells (CTL), and $\mathrm{CD}^{+} \mathrm{CD}^{+} 6^{+} \mathrm{NKT}$ cells in healthy controls (black dots), and COVID-19 patients (gray dots). (D) Ratio of CD4/CD8 absolute numbers cells in healthy controls (black dots) and COVID-19 patients (gray dots). Red lines represent mean values for each population. Data obtained from 19 healthy controls and 27 COVID-19 patients. ${ }^{*} P<0.05 ;{ }^{* *} P<0.01$ ${ }^{* * *} P<0.001$; calculated with Student's $t$ test. interact directly with angiotensin-converting enzyme 2 (ACE2) via the $S$ protein to enter target cells $(12,13)$. It has been recently shown that ACE2 can also mediate SARS-CoV-2 S-dependent entry into cells, thus representing a functional receptor for this newly emerged coronavirus (14). ACE2 is expressed in the respiratory tract, by mucosal epithelial cells, lung alveolar type 2 pneumocytes, and arterial and venous endothelial cells but also in other tissues, including the gastrointestinal tract, accounting for the mild enteritis that sometimes is present in patients with COVID-19 $(15,16)$.

Both innate and adaptive immune responses are critical for the control of viral infections. NK cells exert the primary control during acute viral infection, but cytotoxic $\mathrm{CD} 8^{+} \mathrm{T}$ lymphocytes (CTLs) are critical for long-term surveillance (17-20). The antiviral effects of $\mathrm{NK}$ and $\mathrm{CD}^{+} \mathrm{T}$ cells can be mediated by direct cytotoxicity or through the release of IFN- $\gamma$. IFN- $\gamma$ is able to directly interfere with viral replication, as well as to indirectly affect viral clearance through the activation of Th1-mediated responses and through MHC class I pathway enhancement (21). Antiviral cytotoxic responses are mediated principally by perforin and granzymes. Recovery from viral infections requires the generation of effective antiviral responses that can eliminate, or at least control, the infecting pathogen. Severe viral infections may induce per se immunopathology; however, dysregulated antiviral immune responses can contribute to tissue damage. Thus, it is important to understand the mechanisms regulating pathogen elimination, immunity, and pathology to prevent immune-mediated damage $(22,23)$. In trying to treat common infections, it is important to understand the mechanisms that regulate pathogen elimination, immunity, and pathology so that immune-mediated damage is prevented. The aim of the present study was to perform a deep immunophenotyping of PBMCs from patients affected by COVID-19 and to correlate these data with clinical parameters and outcomes.

\section{Results}

Clinical evaluation of patients with COVID-19. We evaluated 30 patients affected by COVID-19 who were admitted to Careggi University Hospital. SARS-CoV-2 infection was confirmed by positive reverse transcription real-time PCR on nasopharyngeal swab in accordance with WHO interim guidance (24). All specimens were retested and deemed positive for SARS-CoV-2 by the Italian NIH. The clinical characteristics of the 30 patients are shown in Supplemental Table 1 (supplemental material available online with this article; https://doi.org/10.1172/JCI138554DS1). The median age of the patients was 70 years (range $36-85$ years), the mean age was 65.9 years, and $60 \%$ of the patients were male. The mean age was 67.9 years for men and 63 years for women. On the day of the immunological analysis, which was performed on average 9.2 days after the onset of the disease and 3.5 days after the hospital admission, the most common symptoms were fever (53\%) and cough (40\%), whereas diarrhea was an uncommon manifestation (3\%). All patients presented with chest imaging abnormalities (Supplemental Table 1); the most frequent radiological findings were pulmonary consolidations (40\%) and multiple, bilateral, patchy opacities (30\%), compatible with interstitial pneumonia. Supplemental Table 2 reports laboratory results on the day of immunological analysis. Lymphocytopenia (median 830 cells/ $\mu \mathrm{L}$ ) was present in $93 \%$ of the patients, with a median neutrophil/ lymphocyte ratio of 7.3 and eosinopenia (median 20 cells $/ \mu \mathrm{L}$ ) in $52 \%$ of patients. Almost all patients had elevation of acute-phase proteins: C-reactive protein (CRP, median $60.5 \mathrm{mg} / \mathrm{L}$ ), fibrinogen (median $510 \mathrm{mg} / \mathrm{dL}$ ), and ferritin (median $795 \mathrm{ng} / \mathrm{mL}$ ). D-dimer 

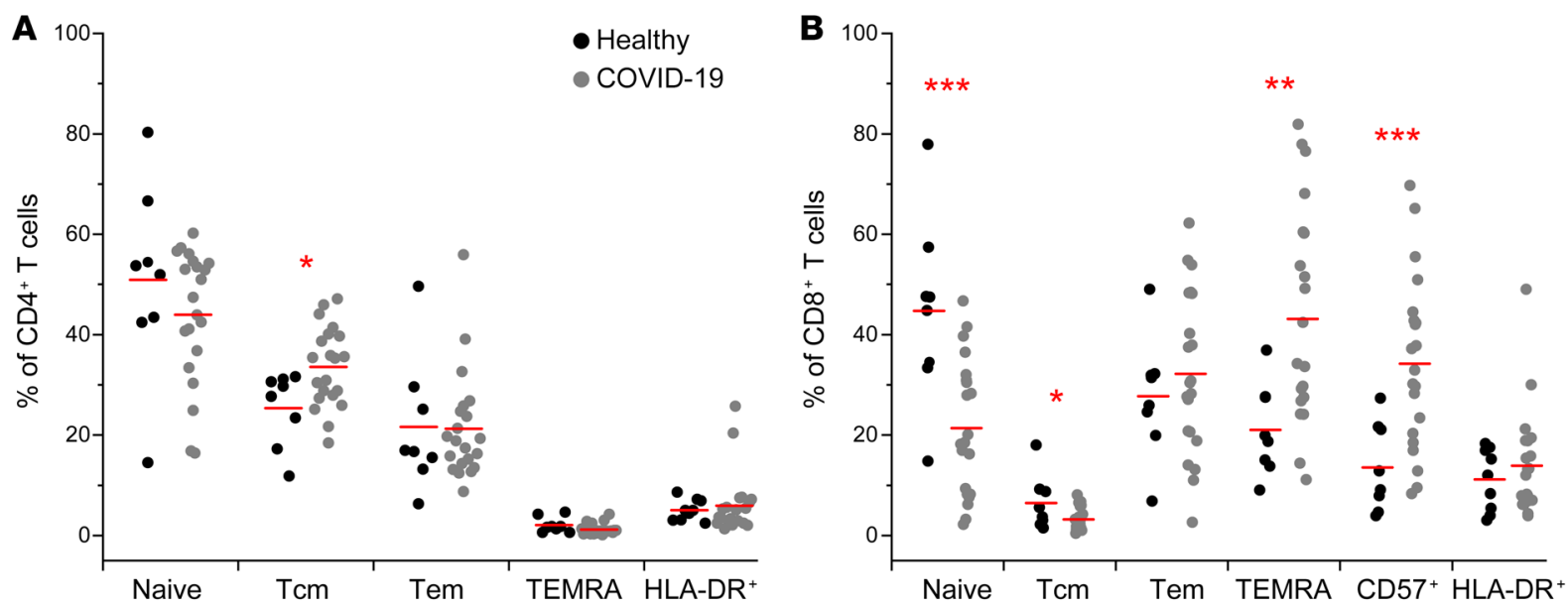

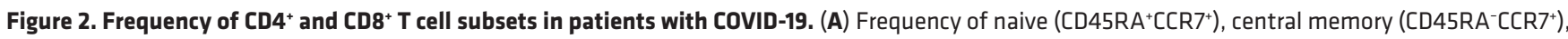
effector memory (CD45RA-CCR7-), TEMRA (CD45RA ${ }^{+}$CCR7 ${ }^{-}$), and HLA-DR cells among CD4 ${ }^{+}$T cells in healthy controls (black dots) and COVID-19 patients (gray dots). (B) Frequency of naive (CD45RA $\left.{ }^{+} C C R 7^{+}\right)$, central memory (CD45RA-CCR7 ${ }^{+}$), effector memory (CD45RA-CCR7-), TEMRA (CD45RA ${ }^{+}$CCR7 ${ }^{-}$), senescent ( $\left(\mathrm{CD}^{+}\right)$, and $\mathrm{HLA}-\mathrm{DR}^{+}$cells among CD8 ${ }^{+} \mathrm{T}$ cells in healthy controls (black dots) and COVID-19 patients (gray dots). Red lines represent mean values for each population. Data obtained from 8 healthy controls and 21 COVID-19 patients. ${ }^{*} P<0.05$; ${ }^{* *} P<0.01$; ${ }^{* *} P<0.001$; calculated with Student's $t$ test.

(median $940 \mathrm{ng} / \mathrm{mL}$ ) and lactate dehydrogenase (median 271 $\mathrm{U} / \mathrm{L})$ were also increased. A majority of the patients $(80 \%)$ had at least 1 comorbidity, and hypertension was present in $50 \%$ of the cases (Supplemental Table 1). Two women were pregnant at 25 weeks of gestation. On the day of analysis, patients were receiving antiviral treatment (83\%), hydroxychloroquine (80\%), and intravenous antibiotics (53\%) (Supplemental Table 1). Oxygen therapy was being administered in $77 \%$ of the patients; the mean $\mathrm{PaO}_{2} / \mathrm{FiO}_{2}$ ratio was 261 (median 268) (Supplemental Table 3). Acute respiratory distress syndrome (ARDS) during the course of COVID-19 occurred in 14 cases (53\%). Among the 30 hospitalized patients considered in this study, $12(40 \%)$ were admitted to the intensive care unit (ICU). ICU patients had more severe pulmonary involvement than patients not admitted to the ICU (mean $\mathrm{PaO}_{2} / \mathrm{FiO}_{2}$ ratio 171 vs. 314, mean $\mathrm{SaO}_{2} / \mathrm{FiO}_{2}$ ratio 170 vs. 372, mean alveolar-arterial $\mathrm{O}_{2}$ gradient $326 \mathrm{vs.} 72 \mathrm{mmHg}$, respectively) $(P<0.001)$. In addition, these patients presented higher neutrophil and lower lymphocyte counts $(P<0.05)$, higher neutrophil/ lymphocyte ratio $(P<0.01)$, higher lactate dehydrogenase $(P<$ $0.001)$, as well as higher CRP $(P<0.05)$ and IL-6 $(P<0.01)$ compared with the non-ICU patients.

Patients with COVID-19 are characterized by lymphopenia. In order to provide direct evaluation of leukocyte homeostasis, we studied the immunological characteristics of peripheral blood leukocytes derived from patients infected with SARS-CoV-2. As shown in Figure 1A, patients with COVID-19 were characterized by a significant increase of neutrophils and a significant decrease of absolute numbers of lymphocytes, eosinophils, and basophils in the peripheral blood as compared with age- and sex-matched healthy controls. Total leukocytes' and monocytes' absolute numbers were comparable between patients with COVID-19 and healthy controls (Figure 1A). In order to better understand which lymphocyte population was affected, we performed a flow cytometric analysis of circulating leukocytes. As shown in Figure 1B, absolute numbers of $\mathrm{T}$ cells $\left(\mathrm{CD} 3^{+}\right)$, B cells $\left(\mathrm{CD}^{-} \mathrm{CD} 19^{+}\right)$, and $\mathrm{NK}$ cells $\left(\mathrm{CD} 3^{-} \mathrm{CD} 56^{+}\right)$were significantly reduced in patients with COVID-19 when compared with healthy controls. In addition, among $\mathrm{CD}^{+}$cells, we found a significant reduction of $\mathrm{CD}^{+}$, $\mathrm{CD}^{+}$, and $\mathrm{CD}^{2} 6^{+}$(NKT) cells (Figure 1C). More importantly, we found that the $\mathrm{CD} 4^{+} / \mathrm{CD}^{+} \mathrm{T}$ cell ratio in patients with COVID-19 was significantly higher than in healthy controls (Figure 1D). The frequencies of TCR $\alpha / \beta-$ and $\gamma / \delta$-positive T lymphocytes showed no significant differences in patients with COVID-19 compared with healthy controls, as well as the frequencies of Treg and $\mathrm{T}$ follicular helper cells (data not shown).

$C D 3^{+} C D 8^{+}$lymphocytes from patients with COVID-19 have a senescent phenotype. Because all lymphocyte populations were significantly reduced in patients with COVID-19, we evaluated, in the context of $\mathrm{B}$ and $\mathrm{T}$ lymphocytes, whether the frequencies of the different subpopulations at different stages of maturation varied.

As shown in Supplemental Figure 1, A-E, although the frequency of naive $\left(\mathrm{IgD}^{+} \mathrm{CD} 27^{-}\right)$, memory-nonswitched $\left(\mathrm{IgD}^{+} \mathrm{CD} 27^{+}\right)$, memory-switched $\left(\operatorname{IgD}^{-} \mathrm{CD} 27^{+}\right)$, and B lymphocytes and plasmablasts $\left(\mathrm{CD} 27^{\mathrm{hi}} \mathrm{CD} 38^{\mathrm{h}} \mathrm{h}\right)$ was not significantly affected, the frequency of transitional $\left(\mathrm{IgM}^{\mathrm{hi}} \mathrm{CD} 38^{\text {hi }}\right)$ B lymphocytes was significantly reduced $(P<0.001)$ in patients with COVID-19 when compared with reference ranges (25).

In the context of $\mathrm{CD} 4^{+} \mathrm{T}$ lymphocytes, we found a significant increase in the frequency of $\mathrm{T}$ central memory $\left(\mathrm{Tcm}, \mathrm{CD} 45 \mathrm{RA}^{-}\right.$ $\left.\mathrm{CCR}^{+}\right)$cells, whereas naive $\left(\mathrm{CD} 45 \mathrm{RA}^{+} \mathrm{CCR} 7^{+}\right)$, $\mathrm{T}$ effector memory (Tem, CD45RA-CCR7 ${ }^{-}$), T effector memory CD45RA ${ }^{+}$(TEMRA, CD45RA ${ }^{+}$CCR7-), and HLA-DR ${ }^{+}$cells from patients with COVID-19 did not show different values when compared with healthy controls (Figure 2A and Supplemental Figure 2). Because the total count of $\mathrm{CD}^{+} \mathrm{T}$ cells was significantly lower in COVID-19 patients than in healthy controls, this finding means that among $\mathrm{CD} 4^{+} \mathrm{T}$ cells, the naive, Tem, and TEMRA subsets were mostly impaired in these patients, whereas $\mathrm{Tcm}$ were relatively conserved.

More importantly, flow cytometric analysis of $\mathrm{CD} 8^{+} \mathrm{T}$ lymphocytes revealed a statistically significant reduction of 

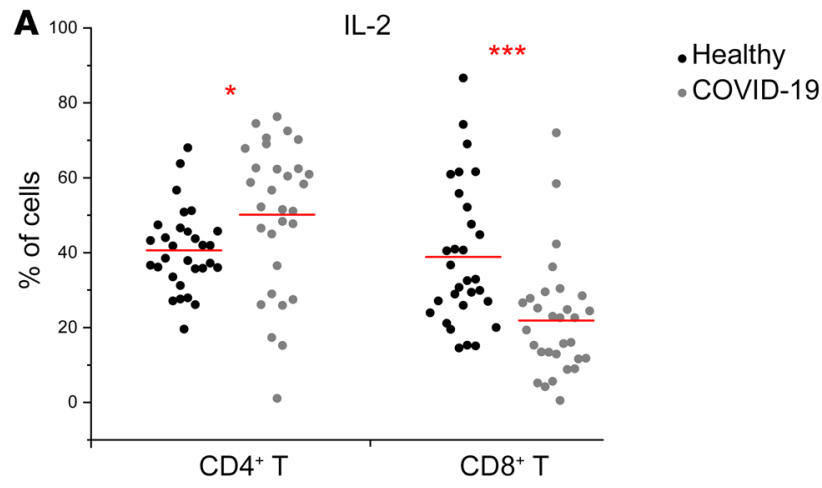

Figure 3. Functional characterization of $\mathrm{CD}^{+}$and $\mathrm{CD8} 8^{+} \mathrm{T}$ cells and $\mathrm{NK}$ cells in patients with COVID-19. (A) Frequency of IL-2-secreting cells among $\mathrm{CD}^{+}$and $\mathrm{CD} 8^{+} \mathrm{T}$ cells after in vitro polyclonal stimulation in healthy donors (black dots) and COVID-19 patients (gray dots). Frequency of IFN- $\gamma$ secreting cells (B) and TNF- $\alpha$ - secreting cells (C) among CD4 ${ }^{+}$and $C D 8^{+} T$ cells and NK cells after in vitro polyclonal stimulation in healthy donors (black dots) and COVID-19 patients (gray dots). Frequency of perforin-expressing cells (D) and granzyme A-expressing cells (E) among $\mathrm{CD}^{+}$and CD8 ${ }^{+} \mathrm{T}$ cells and NK cells in healthy donors (black dots) and COVID-19 patients (gray dots). Data obtained from 30 healthy controls and 30 COVID-19 patients. Red lines represent mean values for each population. ${ }^{*} P<0.05 ;{ }^{* *} P<0.001$; calculated with Student's $t$ test.
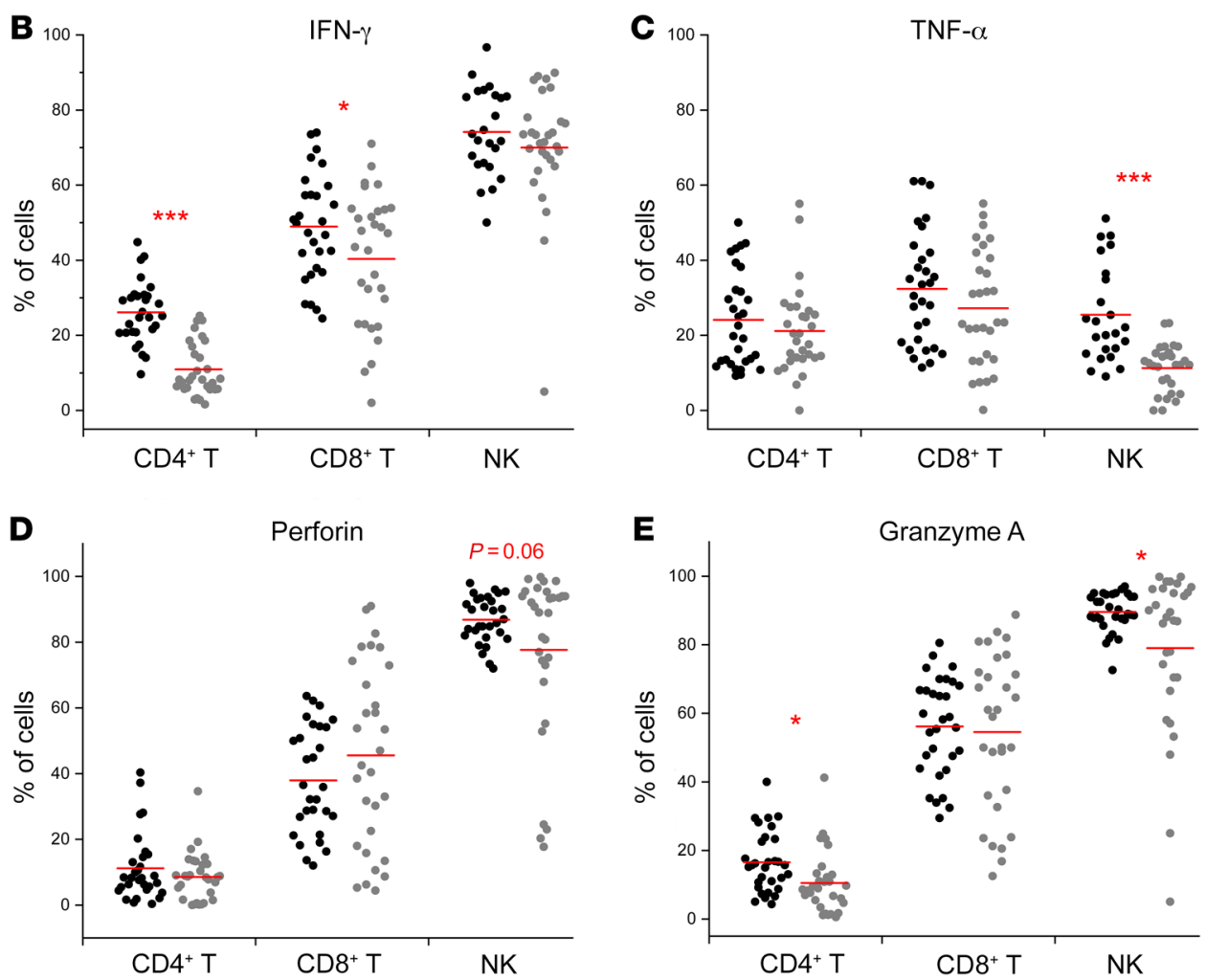

naive $\left(\mathrm{CD} 45 \mathrm{RA}^{+} \mathrm{CCR7}^{+}\right)$and $\mathrm{Tcm}\left(\mathrm{CD} 45 \mathrm{RA}^{-} \mathrm{CCR} 7^{+}\right)$cells in COVID-19 patients when compared with healthy controls (Figure $2 \mathrm{~B}$ and Supplemental Figure 2). In contrast, frequencies of TEMRA (CD45RA $\left.{ }^{+} \mathrm{CCR} 7^{-}\right)$and senescent $\left(\mathrm{CD}^{-} 7^{+}\right) \mathrm{CD}^{+} \mathrm{T}$ cells were significantly higher in COVID-19 patients when compared with healthy controls (Figure 2B and Supplemental Fig-

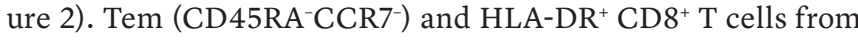
patients with COVID-19 did not show relevant variations when compared with healthy controls (Figure 2B and Supplemental Figure 2). These findings suggest that $C D 8^{+} \mathrm{T}$ cells in patients with COVID-19 are skewed toward a terminally differentiated and senescent phenotype.

Lymphocytes from COVID-19 patients are characterized by significant reduction of type 1 cytokines and cytotoxic potential. After evaluating the different lymphocyte subpopulations in terms of differentiation stages, we stimulated peripheral blood cells with PMA and ionomycin in order to evaluate their ability to produce cytokines (Supplemental Figure 3). In particular, we focused on the cytokines described as being highly protective against viral infections, i.e., IFN- $\gamma$, TNF- $\alpha$, and IL-2. As shown in Figure 3A, patients with COVID-19 showed a significantly increased frequency of IL-2-producing CD4 ${ }^{+} \mathrm{T}$ cells, whereas $\mathrm{CD} 8^{+} \mathrm{T}$ lymphocytes of the same patients showed a significantly reduced frequency of IL-2 when compared with healthy controls.

Patients with COVID-19 showed a significantly reduced frequency of IFN- $\gamma$-producing $\mathrm{CD}^{+}$and $\mathrm{CD}^{+} \mathrm{T}$ cells when compared with healthy controls (Figure 3B). No differences were found in NK cells (Figure 3B) in terms of IFN- $\gamma$ production. Furthermore, patients with COVID-19 showed a significantly reduced frequency of TNF- $\alpha-$ producing NK cells when compared with healthy controls (Figure $3 \mathrm{C}$ ). It should be noted that the $\mathrm{CD}^{+}$and $\mathrm{CD} 8^{+} \mathrm{T}$ lymphocytes also showed a reduced ability to produce TNF- $\alpha$ even if these data did not reach statistical significance (Figure 3C). Because it has been shown that $\mathrm{CD} 4^{+}$and $\mathrm{CD}^{+}$lymphocytes able to produce more than 1 cytokine (polyfunctional $\mathrm{T}$ cells) are most protective against viral infections 
(26), we simultaneously evaluated IL-2, IFN- $\gamma$, and TNF- $\alpha$ expression on a cohort of patients with COVID-19, as well as healthy controls (Supplemental Figure 4A). As shown in Supplemental Figure 4, B and C, although no differences were detected in $\mathrm{CD}^{+}$ $\mathrm{T}$ cells between COVID-19 patients and healthy controls, significantly reduced frequencies of IL- $2^{+}$IFN $-\gamma^{+}$TNF- $\alpha^{+}$and IL- $2^{+}$IFN- $\gamma^{+}$ TNF- $\alpha^{-}$CD $8^{+}$T cells within COVID-19 patients were detected.

Because the antiviral effects of lymphocytes can also be exerted by direct cytotoxicity mediated principally by perforin and granzymes, we evaluated the cytoplasmic expression of these 2 molecules in $\mathrm{CD}^{+} \mathrm{T}$ lymphocytes, $\mathrm{CD} 8^{+} \mathrm{T}$ lymphocytes, and NK cells to define their cytotoxic potential (Supplemental Figure 5). As shown in Figure 3, D and E, NK cells from COVID-19 patients showed significantly reduced percentages of both perforin and granzyme A as compared with healthy donors. Although $\mathrm{CD}^{+} \mathrm{CD}^{+} \mathrm{T}$ cells from COVID-19 patients showed significantly reduced frequencies of granzyme A, no differences were appreciable regarding the frequency of perforin ${ }^{+}$cells in this cell subset and of perforin and granzyme A in the $\mathrm{CD}^{+} \mathrm{CD}^{+} \mathrm{T}$ cell population (Figure 3, D and E).

COVID-19 patients admitted to the ICU show significantly reduced $N K$ cell numbers and cytotoxic potential. A significant fraction of patients with COVID-19 develop ARDS and need hospitalization in the ICU, requiring invasive mechanical ventilation (27). We therefore investigated whether there was a significant variation of the previously identified immune parameters between patients who were admitted to the ICU (ICU patients) and those not admitted to the ICU (non-ICU patients) during the course of hospitalization.

As shown in Figure 4A, ICU patients were characterized by a significant increase of neutrophils' absolute numbers and a significant decrease of lymphocytes' absolute numbers in the peripheral blood as compared with non-ICU patients. Total leukocytes as well as absolute numbers of monocytes, eosinophils, and basophils were comparable between the 2 groups of patients (Figure 4A). As shown in Figure 4B, flow cytometric analysis of circulating leukocytes revealed that absolute numbers of $\mathrm{T}$ cells $\left(\mathrm{CD}^{+}\right)$and NK cells $\left(\mathrm{CD}^{-} \mathrm{CD}^{-} 6^{+}\right)$, but not B cells $\left(\mathrm{CD} 19^{+}\right)$, were significantly reduced in ICU patients compared with non-ICU patients. In addition, among $\mathrm{CD}^{+}$cells, we found a significant reduction of $\mathrm{CD}^{+}$cells, but not $\mathrm{CD}^{+}$and $\mathrm{CD}^{+} 6^{+}$(NKT) cells, in ICU patients compared with non-ICU patients (Figure $4 \mathrm{C}$ ). In the context of $\mathrm{CD}^{+} \mathrm{T}$ lymphocytes, we found no significant differences in the frequency of naive $\left(\mathrm{CD} 45 \mathrm{RA}^{+} \mathrm{CCR} 7^{+}\right), \mathrm{Tcm}\left(\mathrm{CD} 45 \mathrm{RA}{ }^{-} \mathrm{CCR} 7^{+}\right)$, Tem (CD45RA-CCR7 ${ }^{-}$), TEMRA (CD45RA+CCR7'), or HLA-DR ${ }^{+}$ cells between the 2 groups of patients (Figure 4D).

In contrast, flow cytometric analysis of $\mathrm{CD}^{+} \mathrm{T}$ lymphocytes revealed statistically significant reduction of Tem (CD45RA $\mathrm{CCR7}^{-}$) cells and increase of TEMRA (CD45RA ${ }^{+}$CCR7) cells in ICU patients compared with non-ICU patients (Figure 4E). As shown in Figure 4E, naive $\left(\mathrm{CD} 45 \mathrm{RA}^{+} \mathrm{CCR} 7^{+}\right), \mathrm{Tcm}\left(\mathrm{CD} 45 \mathrm{RA}^{-}\right.$ $\left.\mathrm{CCR} 7^{+}\right)$, senescent $\left(\mathrm{CD} 57^{+}\right)$, and $\mathrm{HLA}-\mathrm{DR}^{+} \mathrm{CD} 8^{+} \mathrm{T}$ cells did not differ between the 2 groups of patients (Figure $4 \mathrm{E}$ ).

As shown in Figure 5, A-C, no differences were identified between the 2 groups of patients regarding the frequencies of $\mathrm{CD}^{+} \mathrm{CD}^{+}, \mathrm{CD}^{+} \mathrm{CD}^{+}$, and NK cells producing IFN- $\gamma$, TNF- $\alpha$, and IL-2. Regarding $\mathrm{T}$ cell polyfunctionality, our analysis performed on a cohort of ICU patients and non-ICU patients showed no statistically significant differences between the 2 groups (Supplemental Figure 6).

Finally, the frequencies of both perforin and granzyme A were reduced in NK cells from ICU patients, with statistical significance only for granzyme A (Figure 5, D and E). All together, these data support the concept that in ICU patients the depletion of $\mathrm{CD}^{+} \mathrm{CD}^{+} \mathrm{T}$ cells becomes even more pronounced, as well as the accumulation of terminally differentiated $\mathrm{CD} 3^{+} \mathrm{CD} 8^{+} \mathrm{T}$ cells and NK cells with reduced cytolytic potential, leading to altered immunological protection.

High IL-6 serum levels in ICU patients inversely correlate with NK cytotoxic potential, which can be restored by tocilizumab treatment. Because SARS-CoV-2 infection is reportedly associated with increased IL-6 serum levels (28), we evaluated this proinflammatory cytokine in the sera of ICU and non-ICU patients. As shown in Figure 6A, IL-6 serum levels were significantly higher in ICU patients compared with non-ICU patients. More importantly, among those cellular parameters that we found significantly altered in ICU versus non-ICU patients, we observed a significant inverse correlation only between the serum levels of IL- 6 and the frequency of NK cells expressing granzyme A (Figure 6B).

Because higher serum IL-6 levels correlated with lower granzyme A expression on NK cells, we investigated whether blocking the IL- 6 axis in COVID-19 patients with tocilizumab could restore granzyme A expression. For this reason, we recruited 5 ICU patients as candidates for tocilizumab treatment, characterized by high IL-6 serum levels and low frequency of NK cells expressing granzyme A. Tocilizumab treatment led to a reduction of CRP levels, suggesting that efficacious neutralization of IL- 6 activity was achieved (Figure 6C). As shown in Figure 6D, an increased lymphocyte count was observed after tocilizumab treatment. From a functional point of view, no significant increase was observed in the frequencies of $\mathrm{CD}^{+} \mathrm{T}$ cells expressing granzyme A or perforin (Figure 6, E and F). However, treatment with tocilizumab significantly increased the expression of granzyme $A$ and perforin on NK cells (Figure 6, G and $\mathrm{H}$ ) and induced a mild amelioration of the $\mathrm{PaO}_{2} / \mathrm{FiO}_{2}$ ratio in 4 out of 5 patients (Figure 6I).

\section{Discussion}

Cytotoxic lymphocytes such as $\mathrm{CD}^{+} \mathrm{T}$ lymphocytes and NK cells are necessary for the control of viral infections (17-20), and the functional exhaustion of these cells is correlated with disease progression (29, 30). In contrast, exaggerated or uncontrolled immune responses can be responsible for the organ damage that sometimes accompanies the infection $(16,21)$. The aim of our work was to perform a phenotypic and functional characterization of the immune response in patients infected with SARS-CoV-2 hospitalized at the Careggi University Hospital, Florence, Italy.

We enrolled 30 patients whose main clinical features are reported in Supplemental Table 1. The first clear data point emerging from our analysis was the reduction of circulating lymphocytes compared with a cohort of healthy controls, as already reported (27). Circulating basophils and eosinophils were also significantly lower in patients with COVID-19, whereas neutrophils were higher in patients than in controls. Thus, no differences were observed in the total number of WBCs. By investigating which population of lymphocytes was mainly affected, we found that all subsets, namely 


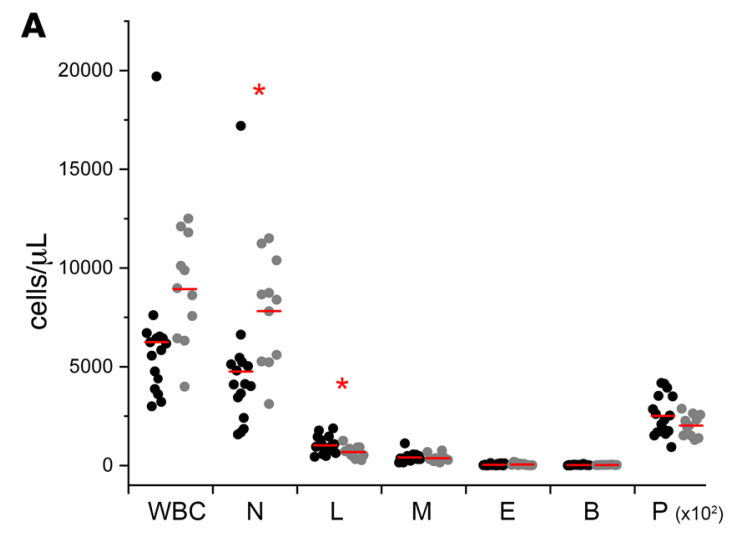

- Non-ICU

- ICU
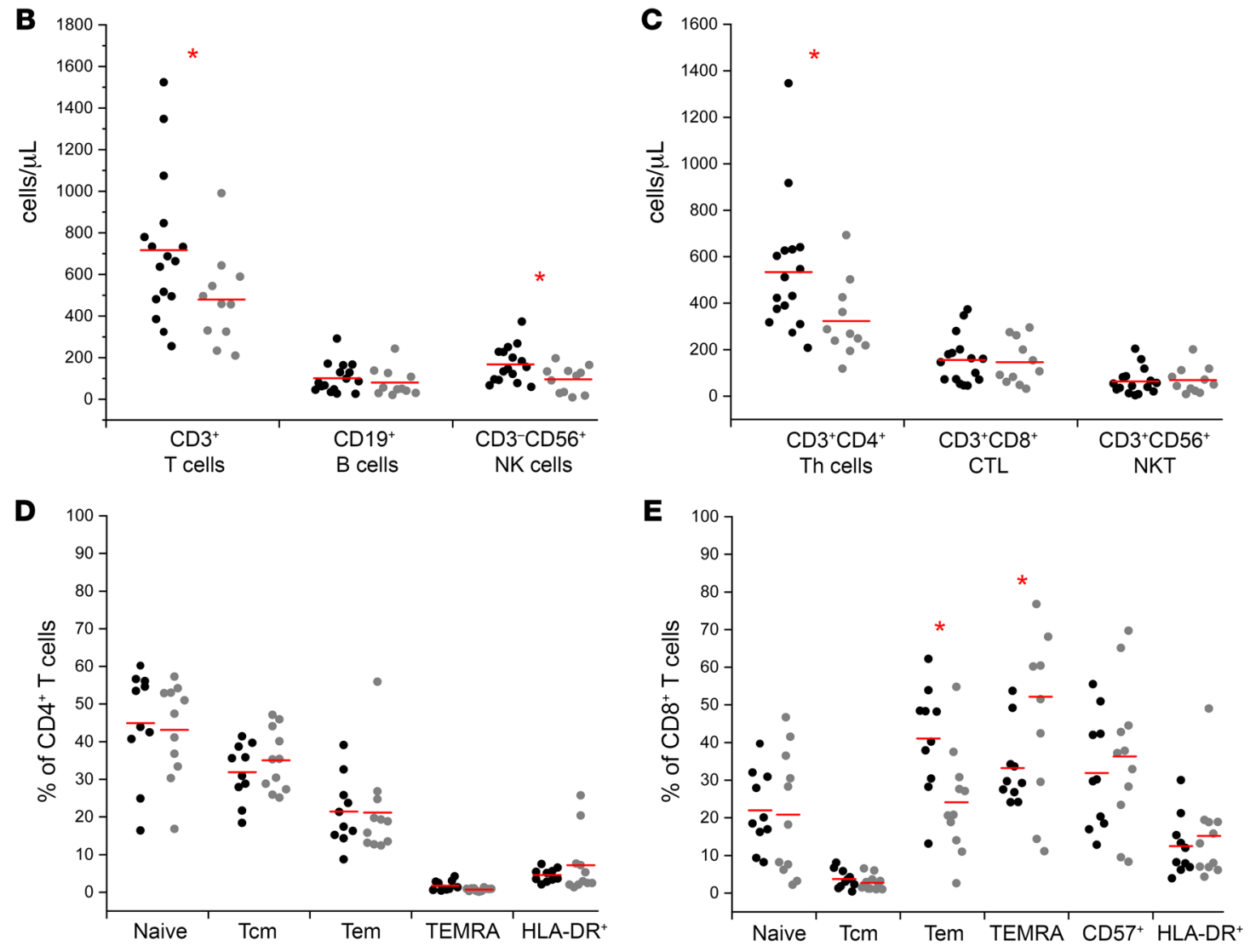

Figure 4. Absolute numbers of immune cell subsets in non-ICU versus ICU hospitalized patients with COVID-19. (A) Absolute numbers of total WBCs, neutrophils $(N)$, Iymphocytes $(L)$, monocytes $(M)$, eosinophils $(E)$, basophils $(B)$, and platelets $(P)$ in non-ICU (black dots) and ICU (gray dots) COVID-19 patients. (B) Absolute numbers of CD3+ ${ }^{+}$cells, CD19+ B cells, and CD56+ NK cells in non-ICU (black dots) and ICU (gray dots) COVID-19 patients. (C) Absolute numbers of $\mathrm{CD3}^{+} \mathrm{CD} 4^{+}$Th cells, $\mathrm{CD3}^{+} \mathrm{CD} 8^{+}$cytotoxic T cells (CTL), and CD3+CD56+ NKT cells in non-ICU (black dots) and ICU (gray dots) COVID-19 patients. (D) Frequency of naive (CD45RA+CCR7 $7^{+}$), central memory (CD45RA-CCR7 ${ }^{+}$), effector memory (CD45RA-CCR7-), TEMRA (CD45RA+CCR7-), and HLA-DR+ cells among CD4 $4^{+} \mathrm{T}^{-}$cells in non-ICU (black dots) and ICU (gray dots) COVID-19 patients. (E) Frequency of naive (CD45RA+CCR7 $7^{+}$, central memory (CD45RA-CCR7 $7^{+}$, effector memory (CD45RA-CCR7-), TEMRA (CD45RA+CCR7-), senescent (CD57+), and HLA-DR+ cells among CD8 ${ }^{+}$T cells in non-ICU (black dots) and ICU (gray dots) COVID-19 patients. Data in A-C obtained from 16 non-ICU and 11 ICU COVID-19 patients. Data in D and E obtained from 10 non-ICU and 11 ICU COVID-19 patients. Red lines represent mean values for each population. ${ }^{*} P<0.05$; calculated with Student's $t$ test.

$\mathrm{T}, \mathrm{B}$, and NK cells, were reduced. Among $\mathrm{CD}^{+} \mathrm{T}$ cells, we found a reduction in both $\mathrm{CD}^{+}$and $\mathrm{CD} 8^{+}$subsets, but also in the $\mathrm{CD} 56^{+}$ fraction, namely the NKT subset. Interestingly, the reduction of the $\mathrm{T}$ cell number was more pronounced in the $\mathrm{CD} 8^{+}$cytotoxic cells than in the $\mathrm{CD}^{+}$Th subset. Despite the reduction of total absolute numbers of B cells in patients with COVID-19, only transitional B cells exhibited substantially lower levels than reference ranges.
This finding, together with a deep characterization of B cell functions, will require additional investigations in the future. The picture was quite different when $\mathrm{T}$ cells, in particular the $\mathrm{CD} 8^{+}$subset, were analyzed. Indeed, we found a marked increase of TEMRA and $\mathrm{CD} 57^{+} \mathrm{CD} 8^{+}$cells with a parallel decrease of the naive subset, indicating an enrichment of senescent cytotoxic $\mathrm{CD} 8^{+} \mathrm{T}$ cells. These data are in agreement with previous studies performed on acute 

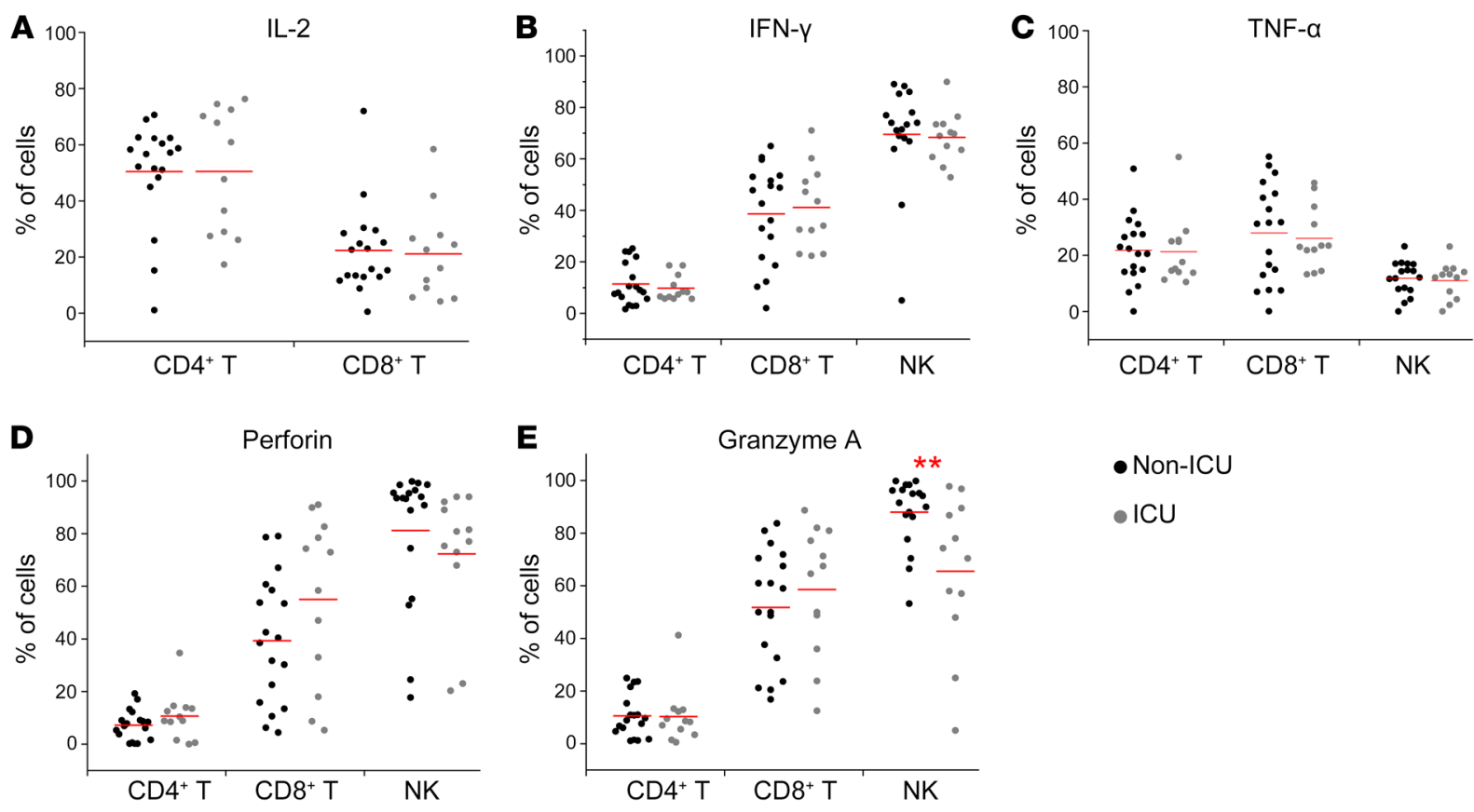

Figure 5. Immune cell functional characterization in non-ICU versus ICU hospitalized COVID-19 patients. (A) Frequency of IL-2-producing cells among $\mathrm{CD}^{+}$and $\mathrm{CD} 8^{+} \mathrm{T}$ cells following in vitro polyclonal stimulation in non-ICU (black dots) and ICU hospitalized patients (gray dots). Frequency of IFN- $\gamma^{+}$(B) and TNF- $\alpha^{+}$(C) cells among CD4+ and CD8 ${ }^{+}$T cells and NK cells after in vitro polyclonal stimulation in non-ICU (black dots) and ICU hospitalized patients (gray dots). Frequency of perforin-expressing cells (D) and granzyme A-expressing cells (E) among CD4+ and CD8 ${ }^{+}$T cells and NK cells in non-ICU (black dots) and ICU hospitalized patients (gray dots). Data obtained from 18 non-ICU and 12 ICU COVID-19 patients. Red lines represent mean values for each population. ${ }^{* *} P<0.01$; calculated with Student's $t$ test.

and chronic viral infections showing that in these conditions, CD8 ${ }^{+}$ T cells acquire an exhausted senescent phenotype $(31,32)$. Accordingly, when we analyzed the ability of $\mathrm{CD} 4^{+}$and $\mathrm{CD} 8^{+} \mathrm{T}$ lymphocytes and NK cells to produce cytokines after polyclonal stimulation in vitro, we found in patients with COVID-19 reduced frequencies of IFN- $\gamma$-producing cells in both $\mathrm{CD} 4^{+}$and $\mathrm{CD} 8^{+} \mathrm{T}$ cells, as well as lower frequencies of TNF- $\alpha$-producing cells among NK cells. Interestingly, patients with COVID-19 showed a significant reduction of $\mathrm{CD}^{+}$polyfunctional cell subsets, which have been described as highly protective in virus-infected patients (26). These findings demonstrated that patients with COVID-19 exhibit not only lower numbers of lymphocytes but also a decreased capacity to produce TNF- $\alpha$ and IFN- $\gamma, 2$ cytokines that play an important role in the clearance of intracellular pathogens (33).

To further explore the capacity of the immune system to clear the infection, we next moved to the evaluation of the cytolytic potential of each lymphocyte subset, and we found that in patients with COVID-19, intracellular expression of granzyme by circulating NK was significantly lower than in healthy controls. Perforin showed the same trend, even if not statistically significant. Collectively, these data demonstrated that COVID-19 patients have a functionally impaired antiviral response.

In order to try to correlate this impairment with disease activity, we divided our cohort of patients in 2 groups, non-ICU patients and ICU patients, searching for differences in terms of immunological functions and/or serological markers of disease activity. Interestingly, when the cytolytic potential was assessed, we found lower frequencies of granzyme A-expressing NK cells in the ICU group compared with the non-ICU group. In addition, the ICU patients showed lower numbers of circulating $\mathrm{CD}^{+} \mathrm{CD} 4^{+}$and NK lymphocytes and higher levels of serum IL-6. Moreover, serum IL-6 levels inversely correlated with the frequency of granzyme A-expressing NK cells. The observation that serum IL-6 levels correlate with the impairment of cytotoxic activity in COVID-19 patients is in agreement with some reports in the literature demonstrating that, both in murine and in human settings, exposure to high levels of IL-6 inhibits NK cell cytotoxicity and downregulates the expression of perforin and granzyme (34-37).

IL-6 is a pleiotropic, proinflammatory, multifunctional cytokine produced by a variety of cell types, whose serum levels are elevated in various inflammatory and autoimmune disorders such as rheumatic diseases and cytokine release syndrome (38). The possibility of using an anti-IL-6 receptor (IL-6R) mAb in COVID-19 patients is emerging as a potential therapeutic option and is currently under evaluation in Chinese and Italian clinical trials $(39,40)$.

Starting from this background, we took the opportunity to evaluate 5 patients with COVID-19 in the ICU who underwent off-label treatment with tocilizumab. These patients were evaluated before and after (72 hours) tocilizumab treatment. All patients treated with tocilizumab displayed an increased expression of both perforin and granzyme A in NK cells and a parallel decrease of CRP, which is considered a marker of IL-6-mediated inflammation. Four out of 5 patients also showed a mild increase of the $\mathrm{PaO}_{2} / \mathrm{FiO}_{2}$ ratio, even if this observation is not sufficient to sustain the claim that tocilizumab has clinical efficacy. Our data are in agreement with studies showing that exuberant inflammatory responses caused by pathogenic human coronaviruses reduce $\mathrm{T}$ cell responses (41). Regarding SARS-CoV infection, this event occurs via a TNF-mediated $\mathrm{T}$ cell 
A
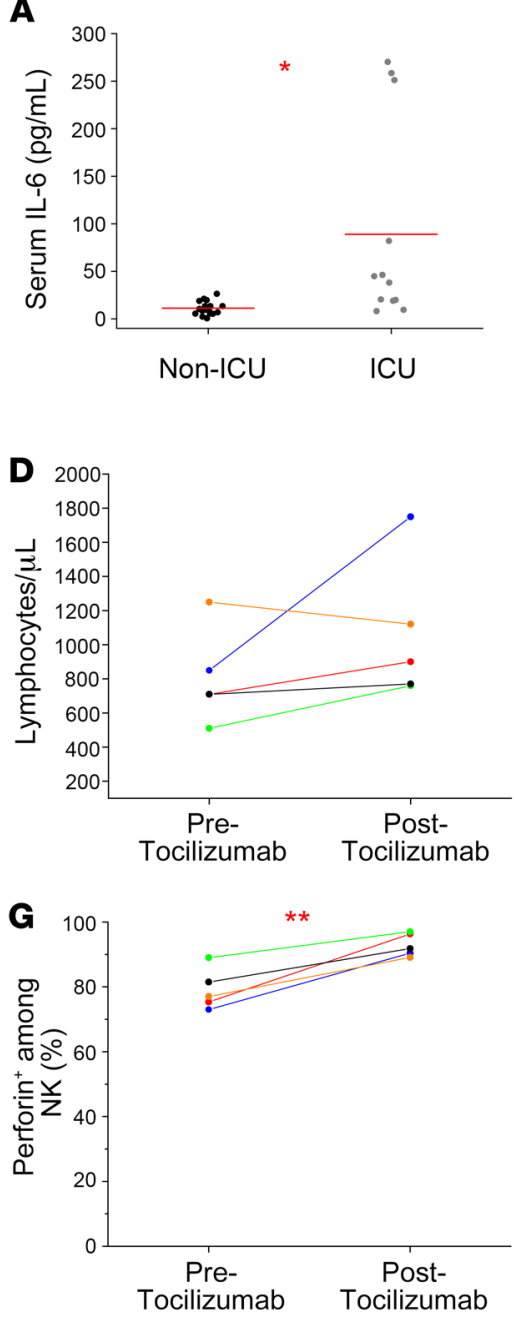

B
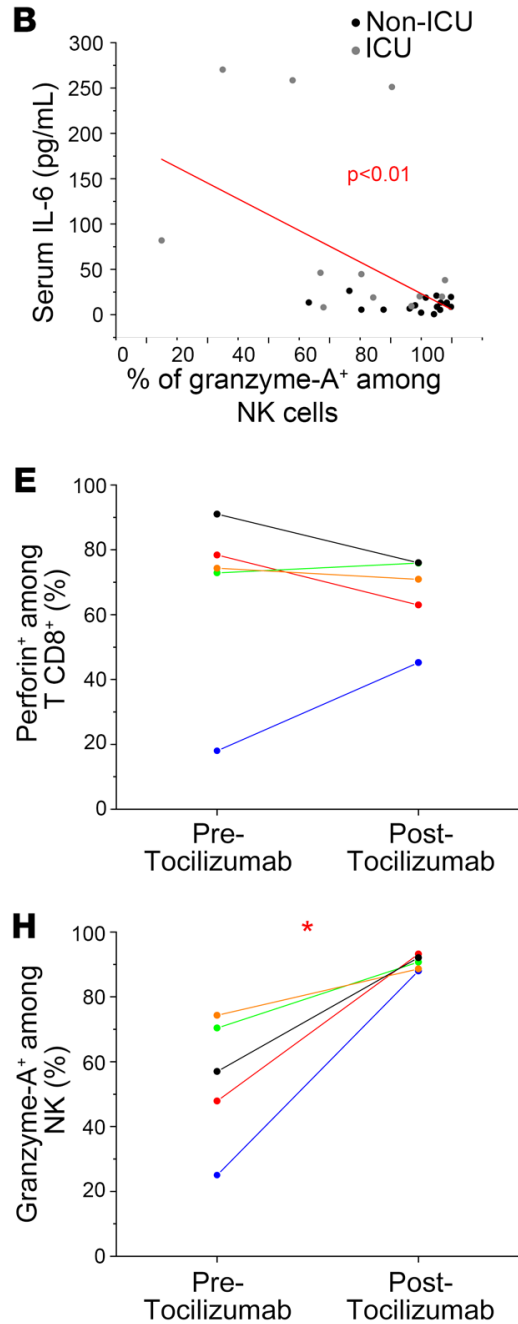
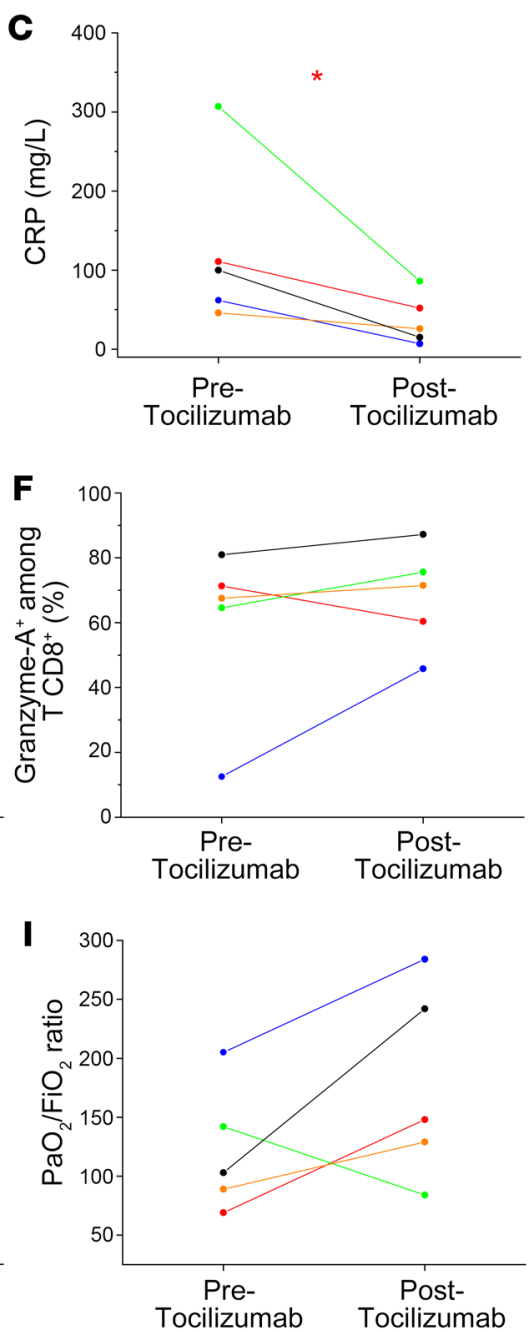

Figure 6. Biological effects of tocilizumab administration in patients with COVID-19. (A) IL-6 serum levels in non-ICU and ICU COVID-19 patients. Red lines represent mean values for each population. ${ }^{*} P<0.05$; calculated with Student's $t$ test. (B) Correlation between serum IL- 6 levels and percentage of granzyme $\mathrm{A}^{+}$cells among NK cells in non-ICU (black dots) and ICU (gray dots) COVID-19 patients, calculated with Pearson correlation coefficient. Red line represents the trend line. Data presented in $\mathbf{A}$ and $\mathbf{B}$ obtained from 30 COVID-19 patients. Evaluation of (C) serum CRP, (D) absolute lymphocyte counts, (E) perforin ${ }^{+}$cells among CD8 ${ }^{+} \mathrm{T}$ cells, (F) granzyme $\mathrm{A}^{+}$cells among $\mathrm{CD} 8^{+} \mathrm{T}$ cells, (G) perforin ${ }^{+}$cells among NK cells, (H) granzyme $\mathrm{A}^{+}$cells among NK cells, and (I) $\mathrm{PaO}_{2} / \mathrm{FiO}_{2}$ ratio in 5 selected ICU COVID-19 patients before and after (72 hours) tocilizumab treatment. Each colored line represents the same patient in all plots. ${ }^{*} P<0.05 ;{ }^{* *} P<0.01$; calculated with Student's $t$ test.

apoptosis, thus resulting in uncontrolled inflammatory responses (42). Indeed, it has been demonstrated that CoV-specific T cells are crucial not only for virus clearance but also for limiting further damage to the host, dampening overactive innate immune responses (43-45). On the other hand, the clearance of the infective agent coincides with the elimination of the trigger that maintains the pathological hyperinflammation.

Our work pointed out some immunological features of COVID-19 patients and focused on cytotoxic lymphocytes as the most impaired subsets. It is important to underline that we enrolled patients who required hospitalization during the course of their disease, and some of them were treated with antiviral agents or even required intensive care. Thus, it is possible that some of the findings highlighted in this work represent a "core" immunological signature that develops at late stages of severe infections. The inverse correlation between serum levels of IL-6 and the impairment of cytotoxic activity suggests the possibility that this cytokine may be responsible for the impairment of cytotoxic lymphocytes, directly or indirectly. This hypothesis is further strengthened by the recovery of perforin and granzyme A expression in NK cells after IL-6R treatment. In this view, the therapeutic blocking of the IL-6 axis should be considered as a mechanism not only to suppress noxious systemic inflammation but also to restore the protective antiviral potential.

In conclusion, the present work suggests that targeting inflammation is a promising tool for the treatment of COVID-19 and provides evidence of the biological mechanism by which tocilizumab can contribute to the clearance of SARS-CoV-2 infection.

\section{Methods}

Patients. Thirty patients infected with SARS-CoV-2 were recruited at the Careggi University Hospital (Azienda Ospedaliero-Universitaria 
Careggi), Florence, Italy, by the Infective and Tropical Diseases Unit and the Intensive Care Units. SARS-CoV-2 infection was confirmed by routine diagnostic PCR amplification of viral genes from nasopharyngeal swabs. Thirty blood donors were recruited as healthy controls. The median age of healthy controls was 63.5 years, the mean age was 64.2 years, and $50 \%$ of the patients were males (Supplemental Table 4). All patients and controls were white. For the longitudinal study, peripheral blood samples were collected before and 72 hours after tocilizumab treatment. Tocilizumab dosage was $8 \mathrm{mg} / \mathrm{kg}$ of body weight, followed by $8 \mathrm{mg} / \mathrm{kg}$ after 12 hours.

Immunophenotyping by flow cytometry. For the analysis of lymphocyte cell subsets by surface marker expression, an aliquot $(600 \mu \mathrm{L})$ of blood specimens was incubated with ammonium chloride for 5 minutes at room temperature (RT) to lyse red blood cells. After 2 washes in PBS plus BSA $0.5 \%$, the resulting WBCs were stained for 15 minutes with fluorochrome-conjugated monoclonal antibodies (mAbs). A list of all fluorochrome-conjugated mAbs is in Supplemental Table 5. Samples were acquired on a BD LSR II flow cytometer (BD Biosciences). All flow cytometric analyses were performed following published guidelines (46).

Evaluation of cytokine production by flow cytometry. PBMCs were obtained after density gradient centrifugation of blood samples. PBMCs were then polyclonally stimulated for 5 hours with PMA $(10 \mathrm{ng} / \mathrm{mL})$ and ionomycin $(1 \mu \mathrm{M})$, the last 3 in the presence of brefeldin $A(5 \mu \mathrm{g} / \mathrm{mL})$. Cells were then fixed in formaldehyde $2 \%$ for 15 minutes at RT, washed in PBS plus BSA $0.5 \%$, and then intracellularly stained with fluorochrome-conjugated $\mathrm{mAbs}$ in the presence of the permeabilizing agent saponin (0.5\%). A list of all fluorochrome-conjugated mAbs used is in Supplemental Table 5. Samples were acquired on a BD LSR II flow cytometer (BD Biosciences).

Evaluation of cytotoxic molecules by flow cytometry. PBMCs were directly fixed and intracellularly stained as previously described using fluorochrome-conjugated mAbs (Supplemental Table 5). Samples were acquired on a BD LSR II flow cytometer (BD Biosciences).

Serum cytokine detection. Dosages of serum IL-6 were performed using an IL-6 human instant ELISA kit (Invitrogen, Thermo Fisher Scientific) on an automated DSX instrument (DYNEX Technologies).
Statistics. An unpaired 2-tailed Student's $t$ test was used for comparison of clinical and laboratory findings and for flow cytometric analysis of healthy controls versus COVID-19 patients and ICU versus non-ICU COVID-19 patients. Paired 2-tailed Student's $t$ test was used for comparison of data obtained before and after tocilizumab administration. $P$ values equal to or less than 0.05 were considered significant. Pearson correlation coefficients were used to calculate the correlations.

Study approval. The procedures followed in the study were approved by the Careggi University Hospital Ethical Committee (protocol 16859). Written informed consent was obtained from recruited patients.

\section{Author contributions}

F Liotta, F Annunziato, L Cosmi, and $\mathrm{AB}$ designed research studies; A Mazzoni, LS, LM, MC, A Vanni, AA, RC, BP, A Matucci, and A Vultaggio conducted experiments; A Mazzoni, LS, LM, MC, MS, JM, LZ, F Liotta, F Almerigogna, and L Cosmi acquired data; A Mazzoni, LS, LM, MC, F Liotta, F Almerigogna, and L Cosmi analyzed data; MS, JM, MT, LZ, LG, L Ciani, CL, PF, F Lavori$\mathrm{ni}, \mathrm{AP}$, and $\mathrm{AB}$ collected peripheral blood samples and acquired informed consent; F Annunziato, LC, F Liotta, A Mazzoni, LS, and LM wrote the manuscript; SR, F Almerigogna, PP, GMR, and OR provided advice. All authors revised the manuscript and gave final approval for publication.

\section{Acknowledgments}

This study was supported by funds from the Department of Experimental and Clinical Medicine of University of Florence (ex-60\% and the "Excellence Departments 2018-2022 Project") derived from Ministero dell'Istruzione, dell'Università e della Ricerca (Italy).

Address correspondence to: Francesco Annunziato, Viale Pieraccini 6, 50139, Florence, Italy. Phone: 39.0552758337; Email: francesco.annunziato@unifi.it.
1. Drosten C, et al. Identification of a novel coronavirus in patients with severe acute respiratory syndrome. N Engl JMed. 2003;348(20):1967-1976.

2. Ksiazek TG, et al. A novel coronavirus associated with severe acute respiratory syndrome. $N$ Engl J Med. 2003;348(20):1953-1966.

3. Zaki AM, van Boheemen S, Bestebroer TM, Osterhaus AD, Fouchier RA. Isolation of a novel coronavirus from a man with pneumonia in Saudi Arabia. NEngl J Med. 2012;367(19):1814-1820.

4. WHO. WHO director-general's opening remarks at the media briefing on COVID-19-11 March 2020. https://www.who.int/dg/speeches/detail/ who-director-general-s-opening-remarks-at-themedia-briefing-on-covid-19---11-march-2020. Updated March 11, 2020. Accessed June 15, 2020.

5. WHO. Coronavirus disease 2019 (COVID-19) situation report-162. https://www.who.int/docs/ default-source/coronaviruse/20200630-covid-19sitrep-162.pdf?sfvrsn=e00a5466_2. Updated June 30, 2020. Accessed June 30, 2020.

6. Coronaviridae Study Group of the International Committee on Taxonomy of Viruses. The species severe acute respiratory syndrome-related corona- virus: classifying 2019-nCoV and naming it SARSCoV-2. Nat Microbiol. 2020;5(4):536-544.

7. Huang C, et al. Clinical features of patients infected with 2019 novel coronavirus in Wuhan, China. Lancet. 2020;395(10223):497-506.

8. Zhou P, et al. A pneumonia outbreak associated with a new coronavirus of probable bat origin. Nature. 2020;579(7798):270-273.

9. Zhu N, et al. A novel coronavirus from patients with pneumonia in China, 2019. N Engl J Med. 2020;382(8):727-733.

10. Lu X, et al. SARS-CoV-2 Infection in children. N Engl J Med. 2020;382(17):1663-1665.

11. Tortorici MA, Veesler D. Structural insights into coronavirus entry. Adv Virus Res. 2019;105:93-116.

12. Ge XY, et al. Isolation and characterization of a bat SARS-like coronavirus that uses the ACE2 receptor. Nature. 2013;503(7477):535-538.

13. Li W, et al. Angiotensin-converting enzyme 2 is a functional receptor for the SARS coronavirus. Nature. 2003;426(6965):450-454.

14. Hoffmann M, et al. SARS-CoV-2 Cell entry depends on ACE2 and TMPRSS2 and is blocked by a clinically proven protease inhibitor. Cell. 2020;181(2):271-280.e8.

15. Hamming I, Timens W, Bulthuis ML, Lely AT, Navis G, van Goor H. Tissue distribution of ACE2 protein, the functional receptor for SARS coronavirus. A first step in understanding SARS pathogenesis. J Pathol. 2004;203(2):631-637.

16. Wan Y, Shang J, Graham R, Baric RS, Li F. Receptor recognition by the novel coronavirus from Wuhan: an analysis based on decade-long structural studies of SARS coronavirus. J Virol. 2020;94(7):e00127-20.

17. [No authors listed]. The involvement of natural killer cells in the pathogenesis of severe acute respiratory syndrome. Am J Clin Pathol. 2004;121(4):507-511.

18. Chen J, et al. Cellular immune responses to severe acute respiratory syndrome coronavirus (SARS-CoV) infection in senescent BALB/c mice: CD4+ T cells are important in control of SARSCoV infection. J Virol. 2010;84(3):1289-1301.

19. Marquardt N, et al. The human NK cell response to yellow fever virus 17D is primarily governed by NK cell differentiation independently of NK cell education. J Immunol. 2015;195(7):3262-3272. 
20. Song H, et al. Monkeypox virus infection of rhesus macaques induces massive expansion of natural killer cells but suppresses natural killer cell functions. PLoS One. 2013;8(10):e77804.

21. Zhou F. Molecular mechanisms of IFN-gamma to up-regulate MHC class I antigen processing and presentation. Int Rev Immunol. 2009;28(3-4):239-260.

22. Duan S, Thomas PG. Balancing immune protection and immune pathology by CD8(+) T-cell responses to influenza infection. Front Immunol. 2016;7:25.

23. Shin EC, Sung PS, Park SH. Immune responses and immunopathology in acute and chronic viral hepatitis. Nat Rev Immunol. 2016;16(8):509-523.

24. WHO. Laboratory testing for coronavirus disease (COVID-19) in suspected human cases: interim guidance. WHO. https://apps.who.int/iris/handle/ 10665/331501. Updated March 19, 2020. Accessed June 15, 2020.

25. Boldt A, et al. Eight-color immunophenotyping of T-, B-, and NK-cell subpopulations for characterization of chronic immunodeficiencies. Cytometry B Clin Cytom. 2014;86(3):191-206.

26. Harari A, Dutoit V, Cellerai C, Bart PA, Du Pasquier RA, Pantaleo G. Functional signatures of protective antiviral T-cell immunity in human virus infections. Immunol Rev. 2006;211:236-254.

27. Guan WJ, et al. Clinical characteristics of coronavirus disease 2019 in China. N Engl J Med. 2020;382(18):1708-1720.

28. Chen G, et al. Clinical and immunological features of severe and moderate coronavirus disease 2019. JClin Invest. 2020;130(5):2620-2629.

29. McLane LM, Abdel-Hakeem MS, Wherry EJ. CD8 $T$ cell exhaustion during chronic viral infection and cancer. Annu Rev Immunol. 2019;37:457-495.
30. Bi J, Tian Z. NK cell exhaustion. Front Immunol. 2017;8:760.

31. Erickson JJ, et al. Acute viral respiratory infection rapidly induces a CD8+ T cell exhaustion-like phenotype. JImmunol. 2015;195(9):4319-4330.

32. Hashimoto M, et al. CD8 T cell exhaustion in chronic infection and cancer: opportunities for interventions. Annu Rev Med. 2018;69:301-318.

33. Annunziato F, Romagnani C, Romagnani S. The 3 major types of innate and adaptive cell-mediated effector immunity. J Allergy Clin Immunol. 2015;135(3):626-635.

34. Tanner J, Tosato G. Impairment of natural killer functions by interleukin 6 increases lymphoblastoid cell tumorigenicity in athymic mice. JClin Invest. 1991;88(1):239-247.

35. Vredevoe DL, Widawski M, Fonarow GC, Hamilton M, Martínez-Maza O, Gage JR. Interleukin-6 (IL-6) expression and natural killer (NK) cell dysfunction and anergy in heart failure. $A m J$ Cardiol. 2004;93(8):1007-1011.

36. Scheid C, Young R, McDermott R, Fitzsimmons L, Scarffe JH, Stern PL. Immune function of patients receiving recombinant human interleukin-6 (IL-6) in a phase I clinical study: induction of C-reactive protein and IgE and inhibition of natural killer and lymphokine-activated killer cell activity. Cancer Immunol Immunother. 1994;38(2):119-126.

37. Cifaldi L, et al. Inhibition of natural killer cell cytotoxicity by interleukin-6: implications for the pathogenesis of macrophage activation syndrome. Arthritis Rheumatol.2015;67(11):3037-3046.

38. Shimabukuro-Vornhagen A, et al. Cytokine release syndrome. JImmunother Cancer. 2018;6(1):56.
39. Chinese Clinical Trial Registry. A multicenter, randomized controlled trial for the efficacy and safety of tocilizumab in the treatment of new coronavirus pneumonia (COVID-19). http://www.chictr.org.cn/showprojen.aspx? proj=49409. Updated February 13, 2020. Accessed June 15, 2020, 2020.

40. EU Clinical Trials Register. Multicenter study on the efficacy and tolerability of tocilizumab in the treatment of patients with COVID-19 pneumonia. https://www.clinicaltrialsregister.eu/ ctr-search/trial/2020-001110-38/IT. Updated March 23, 2020. Accessed June 15, 2020.

41. Channappanavar R, Perlman S. Pathogenic human coronavirus infections: causes and consequences of cytokine storm and immunopathology. Semin Immunopathol. 2017;39(5):529-539.

42. Channappanavar R, Zhao J, Perlman S. T cell-mediated immune response to respiratory coronaviruses. Immunol Res. 2014;59(1-3):118-128.

43. Kim KD, et al. Adaptive immune cells temper initial innate responses. Nat Med. 2007;13(10):1248-1252.

44. Palm NW, Medzhitov R. Not so fast: adaptive suppression of innate immunity. Nat Med. 2007;13(10):1142-1144.

45. Zhao J, Zhao J, Perlman S. T cell responses are required for protection from clinical disease and for virus clearance in severe acute respiratory syndrome coronavirus-infected mice. J Virol. 2010;84(18):9318-9325.

46. Cossarizza A, et al. Guidelines for the use of flow cytometry and cell sorting in immunological studies (second edition). Eur J Immunol. 2019;49(10):1457-1973. 